\title{
Bullets retained within the heart: diagnosis and management in three cases
}

\author{
LUIS SERGIO M FRAGOMENI, PAULO CERATTI AZAMBUJA \\ From the Department of Cardiothoracic Surgery, São Vicente de Paulo Hospital, University of Passo Fundo, \\ Brazil
}

ABSTRACT Three cases of gunshot wounds of the chest are reported, in each of which a bullet waso retained within the heart. Although it is rare, the surgeon should consider this possibility if the missile overlies the cardiac silhouette on the plain chest radiograph. Fluoroscopy played an im= portant part in confirming the diagnosis. Cardiopulmonary bypass was used in all cases and pro vides operating circumstances that improve the prospects of success.

Despite the increasing number of casualties resulting from penetrating chest injuries, retained foreign bodies inside a cardiac chamber are very rare in civilian life. Among the few reports referring to intracardiac bullets or shell fragments, ${ }^{1-9}$ the most interesting and important experience was published by Harken, ${ }^{12}$ based on his second world war experience. More recently, with the increasing sophistication of civilian weapons and in particular their increased calibre and muzzle velocity, a cardiac injury produced by such devices often causes extensive damage and the bullet usually passes right through the heart. Nevertheless, there is always the possibility, depending on the circumstances, that a bullet or a fragment has remained inside the heart. Three cases are described here, in each of which a bullet fired from a low velocity gun lay completely free inside a ventricular cavity after penetrating the muscular cardiac wall.

\section{Case reports}

\section{CASE 1}

A 16 year old girl was taken into hospital 40 minutes after having attempted suicide by shooting herself in the praecordium with a $22 \mathrm{~mm}$ gauge calibre gun. On admission she was pulseless, with the clinical signs of cardiac tamponade. A chest radiograph (fig 1) showed the bullet in the cardiac area and the lateral view showed that the bullet was "out of focus." Fluoroscopy was performed at the same time and showed movement of the bullet, indicating that it was free inside a cardiac chamber, probably the left ventricle.

Address for reprint requests: Dr Luis Sergio M Fragomeni, Minnesota Heart and Lung Institute, 425 East River Road, Minneapolis, Minnesota 55455, USA.

Accepted 19 March 1987
She was immediately taken to the operating theatre and the chest was opened by a median sternotomy After the pericardium had been opened and clot re-moved cardiac function improved immediately. SincE a bullet was known to be within the heart, cardios pulmonary bypass was instituted and the ascending aorta and the superior and inferior venae cavae werE్ cannulated. The aorta was clamped and a cole cardioplegia solution was infused through the as cending aorta. A small perforation was identified on the right ventricular outflow tract. The right ventricle was opened through a small transverse incision and inspection showed that the bullet had also perforate the interventricular septum. The left atrium was opened and a tear in its posterior wall was exposed The bullet was identified in and removed from the lef $\phi$ ventricular cavity, which was inspected through the mitral valve. After the right ventricle, the left atriump and the interventricular septum had been repairea cardiopulmonary bypass was withdrawn. The patien 9 had an uneventful recovery and was discharged from hospital on the 10 th postoperative day. Twent months later she is leading a normal life.

CASE 2

A 21 year old man was admitted to the emergenct department two hours after he had been shot in the left chest with an entrance wound at the left posterios axillary line. He was in haemorrhagic shock with th signs of a left haemothorax, which was confirmed by chest radiography (fig $2 a$ ). There were no clinicat signs of cardiac tamponade. His haemodynamic state was restored and stabilised after the institution of chest drainage and adequate fluid and blood replace 8 ment. After 48 hours he was well and the lungs were fully expanded, but he had a pericardial rub and there 


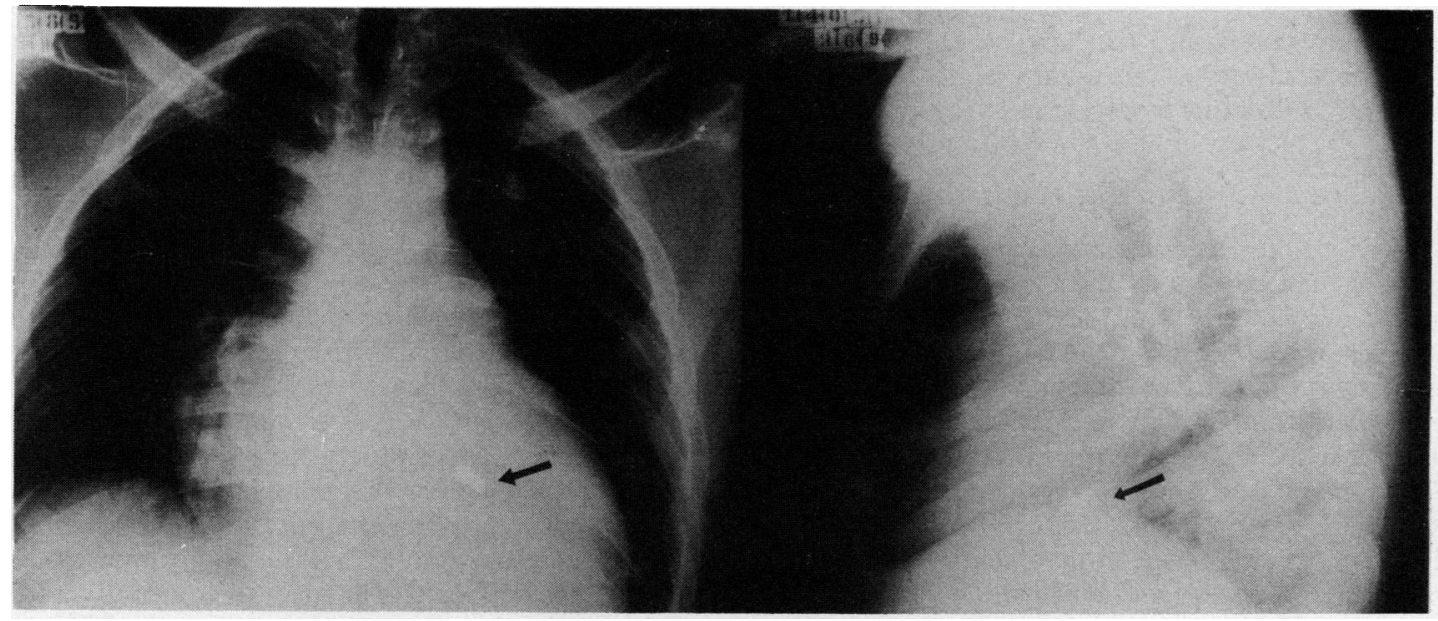

Fig 1 Case 1: Chest radiograph showing the bullet free inside the left ventricular cavity.

were frequent ventricular dysrhythmias. A repeat chest radiograph (fig $2 b$ ) showed mediastinal enlargement, and the bullet's position had changed from that seen on the radiograph taken on admission (fig $2 a$ ). Since it was suspected that a bullet was free inside a cardiac chamber, fluoroscopy was performed and movement of the bullet was noted. The patient was taken to the operating theatre and the sternum was opened. The heart was enlarged and there was no clot in the pericardium. He was put on cardiopulmonary bypass, with cannulation of the ascending aorta and the superior and inferior venae cavae. The aorta was clamped and the heart arrested by cold cardioplegia. A penetrating injury was identified on the back wall of the left ventricle close to the circumflex coronary artery. The left atrium was opened and inspected and the left ventricle approached through the mitral valve. With the mitral valve held wide open a $32 \mathrm{~mm}$ bullet was easily removed from an empty left ventricle. The left ventricle was repaired with Teflon pledgets, the

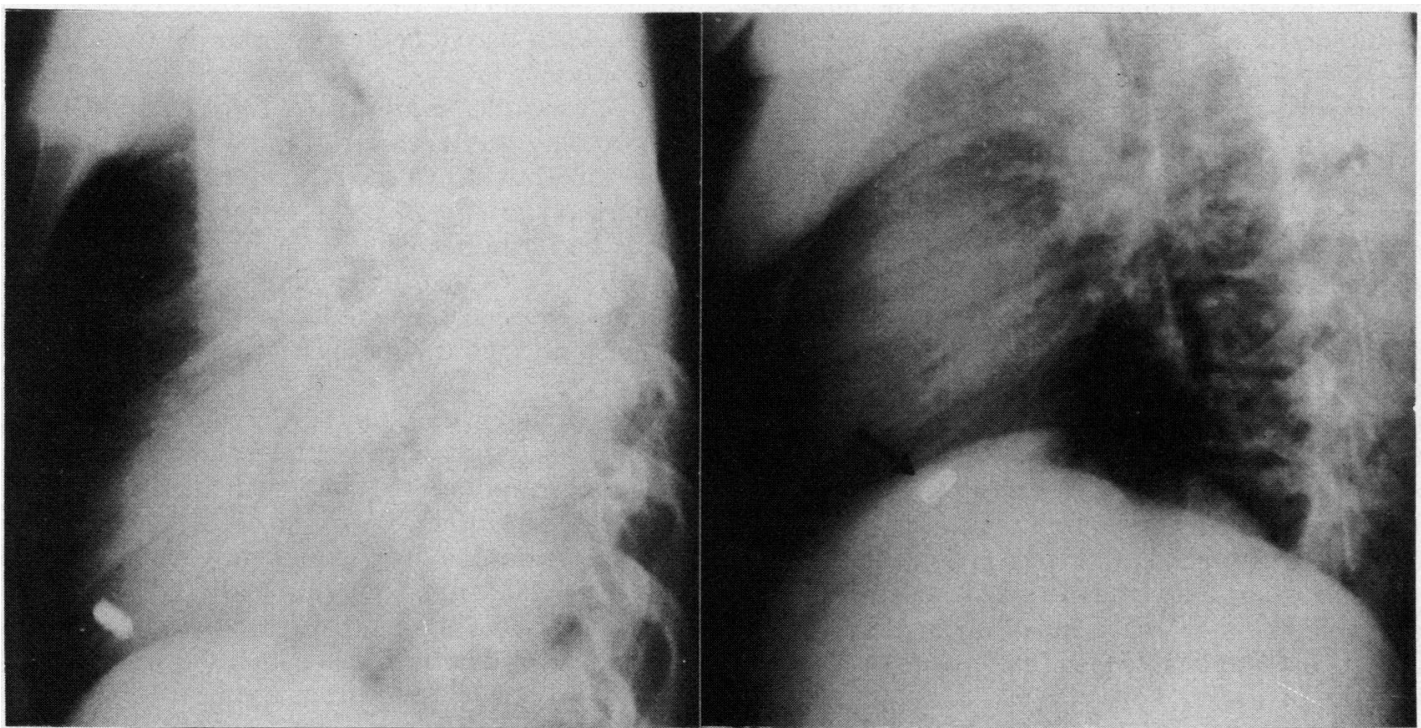

(a)

Fig 2 Case 2: Chest radiographs showing (a) bullet "out of focus" inside the left ventricular cavity, with left haemothorax still present; and $(b)$ the changed appearances 48 hours later, when the left haemothorax had been drained and the bullet had moved into a different position. 
left atrium closed and the heart weaned off cardiopulmonary bypass in the usual manner. The patient made an uneventful recovery and 10 months later is well.

\section{CASE 3}

A 15 year old boy was shot accidentally with a $22 \mathrm{~mm}$ pistol at the lower end of the sternum. Thirty minutes later, when he arrived at the emergency department, he was still conscious but had clinical signs of cardiac tamponade. A chest radiograph showed the bullet, which was "out of focus," to be in the cardiac area without associated haemothorax or pneumothorax. Fluoroscopy performed at the same time showed movement of the bullet, probably inside a cardiac chamber. He was taken to the operating theatre and the sternum opened, and when the pericardium had been relieved of a great quantity of clot cardiac function improved immediately. The heart was inspected and a tear, covered with clot, was identified on the anterior wall of the right ventricle, close to its diaphragmatic surface. Another perioperative radiograph confirmed that the bullet was in the heart. Cardiopulmonary bypass was instituted, with cannulation of the ascending aorta and the superior and inferior venae cavae. The aorta was clamped and the heart arrested with cold cardioplegia. The right ventricle was opened by broadening the initial tear and the bullet was removed from its cavity. The right ventricle was closed with Teflon pledgets and the heart weaned off cardiopulmonary bypass. The boy made an uneventful recovery and is well after one year.

\section{Discussion}

A wide range of penetrating cardiac injuries has been reported from both military and civilian experiences. ${ }^{10-17}$ Battlefield injuries are most frequently fatal; while reports of casualties in civilian life, usually with less damage, suggest that about half of these patients reach hospital alive. They usually present with cardiac tamponade, or are in haemorrhagic shock when the blood drains into a pleural cavity causing haemothorax. The details of the clinical diagnosis of cardiac injury have been described elsewhere ${ }^{510-12}$ and we wish to emphasise here that in special circumstances the suspicion of a retained cardiac foreign body should arise. In cases 1 and 3 it was not only the cardiac tamponade or the site of injury that led us to suspect that the missile was in the heart but the appearance of a missile out of focus on the chest radiograph. In case 2 , as shown in figure $2 a$, the bullet is not as clearly defined as the rest of the film, suggesting that it was moving when the film was taken. As this patient had no clinical signs of cardiac tamponade the bullet's blurred image on the radiograph was initially unnoticed. This particular detail, and the projectiong of the bullet in the cardiac area, should strongly sug $\underline{\underline{\underline{D}}}$ gest that a bullet could be free inside a cardiac cavity The condition of these patients is usually unstable, $s \&$ that a detailed cardiac investigation cannot be undero taken. Fluoroscopy becomes the main method of in $=$ vestigation in these circumstances; it is widely available and simple to perform, can be done quickly $\vec{\omega}_{\vec{\omega}}$ and can confirm whether the bullet moves with the movement of the heart. With experience it can be usect to show that the bullet is free inside a cardiac chami ber. When the patient is in a stable condition, as in case 2 , a different position of the bullet in the cardiac area suggests the possibility of an intracardiac missileog Again, fluoroscopy can confirm the suspicion and at echocardiogram can offer additional information.

It has been difficult to define how frequently a foreign body that has penetrated the heart is in fact lying

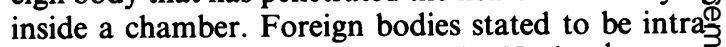
cardiac in many cases referred to by Harken ${ }^{1}$ prove after more accurate fluoroscopy, or at surgery, to be lying outside the heart. More commonly, bullets oog fragments were found remaining in the muscle and sometimes protruding into a cardiac chamber. The arguments for removing them from the heart are te prevent embolisation of the foreign body or assoc: ated thrombus, to reduce the danger of bacteri endocarditis, and to prevent recurrent pleuras effusions and myocardial or coronary damage. ${ }^{19}$ more recent report from Bland and Beebe, ${ }^{7}$ who fo? lowed 40 patients with foreign bodies fixed in the heart over a period of 20 years, showed that effusions were present in $25 \%$ of the cases; the foreign bod was successfully removed in three patients. Pnewo monectomy was necessary in one patient, who had been found to have a shell fragment lodged in the lef pulmonary artery 15 years earlier. All of these pæa tients had a rather benign course during their lives although there was tremendous psychological stres as a result of having a missile in the heart; this factor strongly affected their ability to make a complete res covery.

Less benign is the course of foreign bodies free in cardiac chamber. Fritz and colleagues ${ }^{18}$ experi? mentally introduced 35 foreign bodies directly ints the chambers of the heart in dogs. Only three ref mained within the heart, apparently caught between chordae, while all the others quickly embolised to the pulmonary or systemic circulation. Jones and Helmsworth ${ }^{5}$ described two patients in whom a bullet that had been lodged within the heart embolised 7 one to the inferior vena cava and the other to to origin of the left renal artery.

Harken ${ }^{1}$ emphasised the use of several techniquês for approaching foreign bodies and removing them from the chambers of the heart. The facilities at thist 
time were far less adequate than those of today and this has probably led many surgeons to take a more expectant attitude, rather than advise urgent surgical intervention. In a recent report Zakharia ${ }^{14}$ reported his own extensive personal experience in the Lebanon war, when he operated on 285 patients with cardiac injuries, having removed four intracardiac missiles using inflow occlusion with hypothermia. Our three patients were managed by using cardiopulmonary bypass, a technique seldom required today for the management of other acute cardiac injuries. We believe that intracardiac foreign bodies can be easily dealt with by means of extracorporeal circulation; it is safer to use two caval cannulas than a single cannula in the right atrium. The bullet's exact position is not normally known before the operation, and the use of two venous cannulas permits the right atrium to be opened if necessary. The use of cold cardioplegia and moderate hypothermia $\left(30^{\circ} \mathrm{C}\right)$ is also good practice, producing safe relaxation of the heart, which allows the surgeon to inspect the cavities and locate the foreign body. In our three cases they were easy to locate, but we imagine that they could be difficult to find. In patient No 1 cardiopulmonary bypass was necessary so that the damage to the posterior part of the left atrium could be repaired, as has been noted by others in similar circumstances. ${ }^{1012}$ Without bypass, in cases two and three the bullet could probably have been removed by techniques described in earlier reports. $^{12}$ On the other hand, extracorporeal circulation certainly makes it easier and safer to look for these foreign bodies, especially when their exact position within the heart has not been established preoperatively. Under direct vision, having a certain period of safe ischaemia and a dry field gives a greater chance of success. In addition, all the necessary repairs can be performed at the same time.

Cardiac injuries encountered in civilian practice are usually far less extensive than those produced by modern military weapons. After emergency resuscitation a few victims may be found to have a foreign body lying free in a cardiac chamber, with the consequent risk of embolisation. An intracardiac bullet may be suspected from the site of the entry wound, from the position of the missile on the chest radiograph, and from the blurring of its image through movement. The intracardiac position can be confirmed by fluoroscopy and this should be followed by urgent removal. We believe that the use of cardiopulmonary bypass whenever possible should offer the best conditions for the location and removal of the bullet and for the repair of the myocardial injury while protecting the brain and myocardium from injury due to transient ischaemia.

\section{References}

1 Harken DE. Foreign bodies in, and in relation to, the thoracic blood vessels and heart. III. Indications for the removal of intracardiac foreign bodies and the behaviour of the heart during manipulation. Am Heart J 1946;32:1-19.

2 Harken DE. Foreign bodies in, and in relation to, the thoracic blood vessels and heart. I. Techniques for approaching and removing foreign bodies from the chambers of the heart. Surg Gynec Obstet 1946;33:117-25.

3 Schaefer WB, Satinsky VP. Removal of shell fragment from left ventricle of the heart. Report of a case. Arch Surg 1952;135:13-23.

4 Ricks RK, Howell JF, Beall AC, De Bakey ME. Gunshot wounds of the heart: a review of 31 cases. Surgery 1965;57:787-90.

5 Jones EW, Helmsworth J. Penetrating wounds of the heart: Thirty years' experience. Arch Surg 1968;96:671-82.

6 Bland EF, Beebe GW. Missiles in the heart. A twenty year follow up report of World War II cases. $N$ Engl $J$ Med 1966;274:1039-46.

7 Bland EF. Foreign bodies in and about the heart. Am Heart J 1944;27:588-600.

8 Decker HR. Foreign bodies in the heart and pericardium. Should they be removed? J Thorac Surg 1939;9:62-79.

9 Swan H, Forsee JH, Goyette EM. Foreign bodies in the heart. Ann Surg 1952;135:314-23.

10 Sugg WL, Rea WJ, Ecker RR, Webb WR, Rose EF, Shaw RR. Penetrating wounds of the heart. An analysis of 459 cases. $J$ Thorac Cardiovasc Surg 1968;56:531-45.

11 Bolanowski PJP, Swaminathan AP, Neville WE. Aggressive surgical management of penetrating cardiac injuries. J Thorac Cardiovasc Surg 1973;66:52-7.

12 Symbas PN, Harlaftis N, Waldo WJ. Penetrating cardiac wounds: a comparison of different therapeutic methods. Ann Surg 1976;183:377-81.

13 Zakharia AT. Cardiovascular and thoracic battle injuries in the Lebanon war. J Thorac Cardiovasc Surg 1985;89:723-33.

14 Zakharia AT. Thoracic battle injuries in the Lebanon war: review of the early operative approach in 1992 patients. Ann Thorac Surg 1985;40:209-13.

15 Trinkle JK, Penetrating heart wounds: difficulty in evaluating clinical series [editorial]. Ann Thorac Surg 1984;38:181-2.

16 Grover FL. Treatment of thoracic battle injuries versus civilian injuries [editorial]. Ann Thorac Surg 1985;40:207-8.

17 Tavares S, Hankins JR, Moulton AL, et al. Management of penetrating cardiac injuries: the role of emergency room thoracotomy. Ann Thorac Surg 1984;38:183-97.

18 Fritz JM, Newman MM, Jampolis RW, Adams WE. Fate of cardiac foreign bodies. Surgery 1949;25:869-79. 